\title{
Pensar a escola a PARTIR de Foucault: UMA INSTITUIÇÃO DISCIPLINAR EM CRISE?
}

\author{
FABIO BATISTA \\ Universidade Estadual de Londrina, Londrina, Paraná, Brasil \\ Ana lúcia Pereira Baccon \\ Universidade Estadual de Ponta Grossa, Ponta Grossa, Paraná, Brasil \\ FÁbio Antonio Gabriel \\ Universidade Estadual de Ponta Grossa, Ponta Grossa, Paraná, Brasil
}

\begin{abstract}
Resumo: O presente artigo tem como objetivo apresentar, a partir do filósofo francês Michel Foucault, uma perspectiva sobre o conceito de "disciplina" dentro do contexto escolar na sociedade contemporânea, visto que o aluno de hoje não aceita facilmente as técnicas disciplinares. Para tal, usamos o conceito de poder disciplinar e procuramos caracterizá-la como uma instituição, na qual esse poder se exerce. Apresentamos também algumas reflexões e considerações sobre outra possível escola que busca oferecer uma educação formal mínima aos estudantes, em que possa ser importante para a vida deles, indo além do simples adestramento de indivíduos; a partir de tais pressupostos, restanos saber: a escola atual é uma instituição disciplinar em crise? De acordo com nossa investigação, enquanto um diagnóstico, respondemos afirmativamente a tal questão.
\end{abstract}

Palavras-chave: Foucault. Poder. Disciplina. Escola.

INTRODUÇÃO

Nas últimas décadas, tivemos transformações significativas na sociedade contemporânea: movimento feminista; contracultura nas décadas de 1960-1970; muitas transformações nos costumes e hábitos cotidianos. Com 
certeza, o contexto escolar sentiu diretamente o efeito dessas transformações, provocando alguns questionamentos nos aspectos da identidade dos professores, bem como na sua formação, no papel social da escola e da educação.

Podemos destacar ainda, que, essas transformações afetaram principalmente a relação professor-aluno, pois muito daquilo que funcionava nessa relação, há algumas décadas, não funciona mais nesse novo século. Uma das drásticas transformações é que o professor, muitas vezes, já não consegue manter sua "autoridade" nessa relação; as broncas e os castigos não funcionam mais; indicando que algo se passa no contexto escolar e que algo precisa ser feito.

Toda essa situação remete-nos a questões instigantes: como preparar hoje os trabalhadores da educação para enfrentarem essa crise de identidade? Como deve ser a sua formação? Qual é o papel da educação e da instituição escolar frente à sociedade atual? Qual é o significante novo que deve operar na conexão da relação professor-aluno? A escola, uma instituição disciplinar, está em crise? O que dizer da relação professor e aluno na sociedade contemporânea?

Para delimitar o nosso tema vamos, em primeiro lugar, dedicar um espaço à trajetória de Foucault no início da década de 1970. Isto porque é, sobretudo, na primeira metade dessa década que podemos localizar nosso tema em sua filosofia: a emergência do poder disciplinar e das instituições disciplinares. Por fim, passar-se-á a caracterizar a escola enquanto uma instituição disciplinar em crise: e por que a escola estaria em crise? A partir de Foucault pensamos que o poder disciplinar perdeu sua eficácia funcional e que a crise não se limita a escola, mas à sociedade como um todo. A crise da escola é antes a crise daquilo que Foucault chamou de crise da sociedade disciplinar.

1971-1972 - GRUPO de INFORMAÇÃo SOBRE AS PRISÕES (GIP): PÔR EM XEQUE O PODER DISCIPLINAR?

É possível afirmar que na década de 1960, Foucault fez estudos sobre o poder', contudo, a ele o filósofo dedicou uma atenção mínima. Nos anos de 1960, Foucault se preocupou em especial com os discursos sobre a psiquiatria, a medicina e as ciências humanas. $O$ campo institucional (mais precisamente o poder) ou aquilo que se pode chamar de práticas sociais, teve um lugar limitado por essa época. Foi somente a partir da década de 1970, que Foucault deu ênfase às investigações sobre ele, as quais foram direcionadas por tais questões: quais os tipos de poder? Como eles se exercem em nossas sociedades? Quais são os seus objetos e seus efeitos? De que modo poder e saber se relacionam? 
Sobretudo, durante a primeira metade da década de 1970, Foucault observou que nas sociedades ocidentais (em especial na Europa) havia nascido um tipo de poder, que durante muito tempo se exerceu sem receber muita atenção. Ele o denominou de poder disciplinar. Mas, como Foucault pôde diagnosticar isto? a) Por intermédio de pesquisas que empreendeu em documentos da Bastilha e arquivos relacionados ao Hospital Geral; nos mais variados textos do século XVIII e XIX (por exemplo: regulamentos de instituições; plantas arquitetônicas); b) a leitura de um texto do filósofo e jurista inglês de nome não muito conhecido: Jeremy Bentham (FOUCAULT, 2006).

O texto em apreço era: O panóptico ou a casa de inspeção: contendo a ideia de um novo princípio de construção aplicável a qualquer sorte de estabelecimento, no qual as pessoas necessitem ser mantidas sob inspeção; em particular às casas penitenciárias, prisões, casas para pobres, lazaretos, casas de indústria, manufaturas, hospitais, casas de trabalho, hospícios e escolas. Livro o qual foi escrito no ano de 1787 em Crecheff na Rússia, através de cartas as quais Bentham enviava a um amigo na Inglaterra; ao qual nós retornaremos adiante 2 . Por hora, basta dizer que foi por meio desses vestígios que Foucault pôde elaborar suas hipóteses sobre este novo tipo de poder. E para além desses estudos, uma atividade somou a eles: a militância junto ao Grupo de Informação sobre as Prisões (GIP) - a qual, provavelmente, também contribuiu para o aguçamento e enriquecimento de suas hipóteses (FOUCAULT, 2006).

*

No início da década de 1970, ocorreram duas mudanças fundamentais na vida de Foucault. Primeiramente ele se tornou professor do Collège de France e posteriormente militante junto ao Grupo de Informação sobre as Prisões (GIP) - no qual, Jean Marie Domenach , Foucault e Pierre Vidal-Naquet foram os principais atuantes. Em 8 de fevereiro de 1971 os três assinaram o Manifesto GIP. Distribuído à imprensa e lido por Foucault na capela de Saint-Bernard de Montparnasse. Mas, ainda resta uma dúvida: por que nasceu este grupo?

Em 27 de maio de 1970, depois da dissolução do movimento de inspiração maoísta chamado Esquerda Proletária, numerosos militantes foram presos por reconstituição de liga dissolvida, delito do qual fazia parte a simples venda do jornal La cause du peuple. Em setembro de 1970, e novamente em janeiro de 1971, os militantes prisioneiros empreenderam uma greve de fome para serem reconhecidos como prisioneiros políticos, status que acarretava alguns direitos de reunião. Eles almejavam também atrair a atenção sobre o sistema penitenciário (FOUCAULT, 2003, p. 1). 
Michel Foucault, por sugestão de Daniel Defert, então resolveu criar este grupo para apoiar os prisioneiros maoístas, estando assim em consonância com o propósito deles, colocando em xeque a própria prisão enquanto instituição. Para tanto, o grupo mobilizou também os prisioneiros de direito comum e também suas famílias. Dessa forma, o objetivo era dar voz aos prisioneiros, às suas famílias e também àqueles que pela prisão já haviam passado. Não se tratava dos intelectuais falarem pelos prisioneiros, mas ao contrário, os intelectuais, apenas proporcionavam os meios pelos quais eles poderiam dirigir se à sociedade. "A denúncia das condições materiais da detenção, a circulação da informação, a reapropriação do saber e a resistência são, assim, dimensões intimamente vinculadas pelos militantes do GIP" (REVEL, 2011, p. 72). Muitos foram militantes no GIP - de intelectuais mais conhecidos como Deleuze e Sartre, a jornalistas, médicos e advogados. Na verdade, o GIP teve efeitos interessantes na sociedade francesa (FOUCAULT, 2006).

Um dos primeiros foi a entrada da imprensa cotidiana e das rádios nas prisões, até então interditadas, [...]. Esse suporte exterior encorajou um movimento de revolta que sacudiu 35 estabelecimentos, [...]. O GIP contribuiu para inflectir o militantismo posterior a 1970. Baseados em seu modelo, foram criados o GIS, ou Grupo de Informação-Saúde, retirando a compartimentagem entre médicos e doentes, o GIA, ou Grupo de Informação sobre os Asilos, o GISTI, ou Grupo de Informação e Suporte aos Trabalhadores Imigrados (FOUCAULT, 2003, p. 1).

Além de possibilitar a fala dos prisioneiros e a troca de informações entre as pessoas que estavam fora e as que estavam dentro das prisões, o GIP contribuiu para a disseminação de um modelo de militância adotado em outros setores como citamos acima. $\mathrm{O}$ importante é que as instituições que até aquele momento passaram despercebidas começaram a ser questionadas. Sobretudo, as relações que dentro delas se travavam entre aqueles que nela trabalhavam e os que nela viviam. Como no caso das prisões e asilos, ou dos hospitais em que as pessoas não chegam a morar, mas que por lá passam. Foucault afirmou mais tarde que existe/ia uma identidade entre estas instituições. O quê? O tipo de poder que dentro delas se exercem é o mesmo: a disciplina. Mas, ainda não é hora de tratarmos desse assunto.

Em 15 de março de 1971, o GIP lança sua primeira inquirição. Uma espécie de questionário que circulou junto aos presos, ex-presos e suas famílias. Depois foi organizado para uma distribuição na sociedade como um todo:

O Grupo de Informação sobre as Prisões acaba de lançar sua primeira inquirição. Não é uma inquirição de sociólogos. Trata-se de dar a palavra 
àqueles que têm uma experiência da prisão. Não porque eles precisem que os ajudemos a 'tomar consciência': a consciência da opressão está ali, perfeitamente clara, sabendo muito bem quem é o inimigo. Mas, o sistema atual lhe recusa os meios de se formular, de se organizar. [...] É preciso que essas experiências, essas revoltas isoladas se transformem em saber comum e em prática coordenada. [...]. Nossa inquirição não foi feita para acumular conhecimentos, mas para aumentar nossa intolerância e fazer dela uma intolerância ativa (FOUCAULT, 2003, p. 4).

As atividades do GIP trouxeram uma nova concepção de ação para os intelectuais e suas lutas. Não se tratava de lutas universais, mas, locais e o intelectual deixava também de ser a voz universal dos oprimidos, a consciência universal dos que sofrem. Aos prisioneiros, de acordo com o GIP, não faltava à consciência de que a prisão é um instrumento de repressão social, mas faltavam-Ihes os meios que pudessem falar e denunciar as condições nas quais eles se encontravam. E, de acordo com Revel, o GIP constitui para Foucault um momento de transição (FOUCAULT, 2006). Embora seu interesse pela prisão esteja inicialmente

envolvido num questionamento mais amplo sobre os modelos e as modalidades de encarceramento (os quais ele havia desenvolvido previamente, na década de 1960, no âmbito de uma história da loucura, e, depois, em uma história da clínica), com certeza o militantismo no interior do GIP Ihe possibilita redirecionar suas pesquisas tanto na direção de uma analítica dos poderes (que culminará, em 1975, no livro Vigiar e punir) quanto na direção de uma descrição atenta dos processos de subjetivação (REVEL, 2011, p. 73).

Isto é, como tentamos mostrar ao longo desta seção, o GIP foi de extrema importância ao pensamento de Foucault. Sua militância contra as prisões, já ligava se à perspectivas teóricas mais antigas, relacionadas à história do encarceramento no Ocidente. Mas, o ajudou a perceber e a formular novas concepções sobre o poder. Saindo do âmbito de uma análise institucional em que o poder tem a função de repressão, para uma análise das relações de poder o qual é produtivo. Vejamos isto em sua trajetória.

PODER: INTERNAR (REPRIMIR), DISCIPLINAR (PRODUZIR)

É provável que o tema do poder em Foucault tenha surgido em seu primeiro livro de importância: História da loucura na idade clássica, publicado em 1961, o qual é em sua origem, sua tese doutoral. Apresenta as transformações que a loucura e o louco passaram desde o Renascimento 
até o século XIX; no âmbito discursivo e não-discursivo. A temática do poder é estudada aí, quando Foucault descreveu o ato de internamento em várias instituições entre os séculos XVII e início do XIX. Ato que, de acordo com Foucault, teve um significado de repressão. $O$ exemplo maior de tal prática é a fundação do Hospital Geral na França em 1656, o qual era "[...] antes uma estrutura semi-jurídica, uma espécie de entidade administrativa que, ao lado dos poderes já constituídos, e além dos tribunais, decide, julga e executa" (FOUCAULT, 2008, p. 50). Foucault mostra como esse poder era exercido; de que meios e instrumentos os diretores dos estabelecimentos se valiam para julgar e executar. Era todo um instrumental à disposição para fazer reinar uma ordem no interior de seus prédios e, por vezes, fora. Eram eles: "postes, golilhas de ferro, prisões e celas no dito Hospital Geral e nos lugares dele dependentes conforme for de seu parecer (...)" (Édito de 1656 apud. FOUCAULT, 2008, p. 50). Assim, fica claro que, se esse estabelecimento recebesse o nome de hospital ele não tinha o significado e função que hoje recebe. Em tal estabelecimento, o que se procurava era antes assistir e punir seus habitantes do que estabelecer qualquer cuidado médico. Foucault afirmou que, se havia um médico no Hospital Geral que visitava todos os seus prédios, era antes para evitar doenças nesses lugares. De fato, os prédios do Hospital Geral eram muito parecidos com a prisão. Vejamos: "se há um médico no Hospital Geral, não é porque se tem consciência de que aí são internados doentes, é porque se teme a doença naqueles que já são internados" (FOUCAULT, 2008, p. 115).

Embora, na década de 1960, Foucault tenha publicado outros livros, o tema do poder perdeu espaço. Retornando timidamente em fins de 1970 com sua aula inaugural no Collège de France: $A$ ordem do discurso. Seu lugar, contudo, no pensamento de Foucault ficou evidente em 1971 no artigo:"Nietzsche, a genealogia e a história", no qual, não só o tema do poder apareceu, como outro tema e conceito importante dos próximos anos de seus estudos: o corpo. Mas, se aí o poder é tema de destaque ele aparece sobre outra perspectiva. Aparece ao lado do saber. Poder e saber se encontram inevitavelmente imbricados, em que um se apoiaria no outro. Um exemplo disso, apresentado em Vigiar e punir é o exame. O exame, de acordo com Foucault, é uma forma de sobreposição de poder e saber que atua sobre nós, nas mais variadas áreas: nas escolas, nos hospitais, etc. E na esteira desta imbricação, outra novidade ainda maior dessa época: o poder de acordo com Foucault é positivo; ele não só reprime e diz não, como ele o apresentou na 
década de 1960: pois, do contrário como ele poderia se perpetuar? Como seus efeitos poderiam produzir saber sobre os indivíduos, e em última instância, produzir até mesmo os indivíduos.

Mas, se o poder fora fundamental junto a outros conceitos na primeira metade da década de 1970, nem por isso Foucault forneceu uma teoria acerca dele. Produziu estudos históricos, a partir dos quais pôde descrevêlo em seus modos de exercício. A única exceção talvez seja uma pequena parte em História da sexualidade Vol. I, em que Foucault fez considerações metodológicas acerca do poder. E posteriormente, já na década de 1980 em um artigo ele novamente expõe suas concepções relacionadas ao poder: "O sujeito e o poder". Contudo, tratava-se mais de esclarecimentos de ordem metodológicas do que estabelecer uma unidade teórica sobre o poder.

Vejamos agora como ele trabalhou sobre um tipo específico de poder, chamado de disciplina, ou poder disciplinar. E como ele pode ser pensado no âmbito da escola.

\section{ESCOLA E PODER DISCIPLINAR}

Sabe-se que Foucault jamais se ocupou com a educação em seus textos. No máximo se referiu à escola e isto porque ela era uma entre tantas outras instituições modernas importantes.

Também, não encontramos em Foucault uma investigação sobre as instituições, ${ }^{3}$ mas das relações de poder. E é somente apropriando-se de seu pensamento, que poderemos propor e efetivar uma análise como esta: escola e poder disciplinar. Nisto há uma vantagem: ao fazermos uso de seu pensamento, talvez possamos ir além do mero comentário. Sem, contudo, desfigurá-lo.

É a partir do século XVIII, que mecanismos ou novas tecnologias políticas de poder adentram, tornam-se parte da vida cotidiana das pessoas. Este poder é denominado por Foucault de "disciplina". E vale dizer: é uma tecnologia positiva de poder. Pois, como veremos "fabrica" corpos. Não como uma fábrica de carros, mas na medida em que o corpo tem sua maleabilidade, ele o sujeita e o torna dócil e útil. Um exemplo nítido disto é a disciplina no âmbito militar, que faz de um homem um soldado ágil, forte, hábil e obediente.

Foucault, ao analisar vários documentos do século XVIII e XIX, percebeu que professores, médicos, oficiais do exército, sempre mencionavam a palavra disciplina, de modo que ele pôde concluir que este termo se referia a um conjunto de técnicas para o adestramento do corpo: fosse 
ele do aluno, do soldado, do doente, ou daquele que trabalhava em uma fábrica. Portanto, ele observou que a noção de disciplina denotava meios para fabricar, formar, corrigir e reformar corpos. Ora, mas como delimitá-la, defini-la? Podemos assim fazer:

A modalidade, enfim: implica numa coerção ininterrupta, constante, que vela sobre os processos da atividade mais que sobre seu resultado e se exerce de acordo com uma codificação que esquadrinha ao máximo o tempo, o espaço, os movimentos. Esses métodos que permitem o controle minucioso das operações do corpo, que realizam a sujeição constante de suas forças e lhes impõe uma relação de docilidade-utilidade, são o que podemos chamar as "disciplinas" (FOUCAULT, 2009, p. 133, itálico nosso).

Nota-se que esquadrinhar, isto é, delimitar, demarcar, direcionar minuciosamente o tempo, o espaço, e os movimentos são meios importantes para os fins do poder disciplinar, os quais se condicionam a controlar as operações do corpo, de modo que ele seja útil e dócil ao mesmo tempo. O corpo, doravante deve ser um mecanismo da maquinaria da sociedade moderna capitalista; corpo que passa de instituição a instituição. Assim, o homem moderno é aquele que passa a maior parte de sua vida dentro de instituições. Contudo, Foucault não deseja fazer a história das diversas instituições para demarcar o que cada uma poderia ter de singular; mas, a partir delas localizar as técnicas do poder disciplinar que de uma instituição a outra se generalizam mais facilmente:

Técnicas sempre minuciosas, muitas vezes ínfimas, mas que têm sua importância: porque definem certo modo de investimento político e detalhado do corpo, uma nova "microfísica" do poder; e porque não cessaram, desde o século XVII, de ganhar campos cada vez mais vastos, como se tendessem a cobrir o corpo social por inteiro (FOUCAULT, 2009, p. 134).

Primeiro: a importância de tais técnicas residiria em sua novidade, tendo em vista que é uma nova tecnologia política de poder, que investe de modo detalhado o corpo; ${ }^{4}$ que o forma e o reforma; que o torna apto as mais diversas atividades: por exemplo: o modo como o soldado deveria manusear um fuzil; qual a posição correta para um estudante escrever com precisão e agilidade; como um operário deveria manusear seus instrumentos de trabalho. Pode-se desse modo, observar que o poder não mais destrói o corpo através de suplícios; como se dava antes com o poder monárquico, mas o torna instrumento a ser utilizado. Isto é, há uma passagem ainda que 
gradual, dos suplícios, esse tipo de execuções públicas, para um poder de manutenção do corpo (FOUCAULT, 2009).

Segundo: tais técnicas estariam, cada vez mais, a ocupar espaço em nossas sociedades, indo além do âmbito de uma instituição ou outra, atravessando todas e além delas. Sejam elas escolas, hospitais, organizações militares, hospícios, asilos, família.

Ora, mas quais seriam estas técnicas? Eis a primeira: aquilo que Foucault chamou de a arte das distribuições; a qual está dividida em quatro momentos que se cruzam e se complementam. Ela se encontra em Vigiar e punir, cujo capítulo tem um título bastante sugestivo: "corpos dóceis".

PRIMEIRo: o princípio de clausura, ou a cerca: isto é, um lugar fechado em si mesmo. Por exemplo: Colégios: o modelo do convento se impõe pouco a pouco; o internato aparece como o regime de educação senão o mais frequente, pelo menos o mais perfeito. Quartéis: é preciso fixar o exército; impedir a pilhagem e as violências; fazer cessar as deserções; controlar as despesas.

SeGUNDO: quadriculamento: cada indivíduo no seu lugar; e em cada lugar, um indivíduo. Importa estabelecer as presenças e ausências, saber onde e como encontrar os indivíduos, poder a cada instante vigiar o comportamento de cada um.

TERCEIRO: localizações funcionais: lugares determinados se definem para satisfazer não só a necessidade de vigiar, de romper as comunicações perigosas, mas também de criar um espaço útil.

QUARTO: fila: a ordenação por fileiras, no século XVIII, começa a definir a grande forma de repartição dos indivíduos na ordem escolar: filas de alunos na sala, nos corredores, nos pátios; alinhamento das classes, de idade, umas depois das outras; sucessão dos assuntos ensinados, das questões tratadas segundo uma ordem de dificuldades crescentes.

A segunda técnica e não menos importante, seria o controle da atividade: 1) o horário: é uma velha herança. As comunidades monásticas haviam, sem dúvida, sugerido seu modelo estrito. Ele se difundiria rapidamente. Seus três grandes processos - estabelecer as censuras, obrigar a ocupações determinadas, regulamentar os ciclos de repetição - muito cedo foram encontrado nos colégios, nas oficinas e hospitais. Nas escolas elementares, a divisão do tempo torna-se, cada vez mais, esmiuçante; as atividades são cercadas o mais possível por ordens a que se tem que responder imediatamente. No começo do século XIX, serão propostos para a escola, horários como o seguinte: 8 h45 entrada do 
monitor; 8h52 chamada do monitor; 8 h56 entrada das crianças e oração; 9h entrada nos bancos; 9h04 primeira lousa; 9 h08 fim do ditado; 9h12 segunda lousa, etc. O que se pretende com tudo isso é: exatidão; aplicação; regularidade (FOUCAULT, 2009).

Como se vê são técnicas, que podem ser localizadas ora em um colégio, ora em um hospital e assim por diante, isto é, as técnicas do poder disciplinar não se limitam ao espaço de uma única instituição.

No caso das escolas que temos hoje, existe algum resquício dessas técnicas nelas? Tudo indica que sim. Temos, por exemplo, a ideia de que cada aluno deve ocupar um lugar na sala de aula; em cada carteira um aluno e cada aluno em uma carteira e que deste lugar ele seja localizável, observável, passível de classificação e avaliação, enfim, que no lugar no qual ele se encontra seu comportamento possa ser vigiado, seus gestos registrados; e que neste lugar ele desenvolva as suas atividades. Quanto às filas: é aquilo que fica mais evidente como herança dessas técnicas. Filas para a entrada; filas das carteiras em sala; filas para o refeitório. E obviamente, tudo sempre com horários definidos para o início das aulas, para o intervalo e assim por diante. Nesse âmbito, a noção de ordem está muito próxima das técnicas disciplinares. Teve-se com elas, a partir do uso delas o sonho de uma sociedade perfeita. Uma sociedade em ordem, no qual, o menor desvio fosse detectado. É todo um investimento do detalhe que se fez. O poder disciplinar é o poder que se ocupa do detalhe do ínfimo. Nada deve passar despercebido; pelo contrário, tudo deve ser observado.

Por vezes, a própria disposição arquitetural das escolas está a serviço de tais técnicas. É a ideia anunciada por Bentham, em fins do século XVIII em seu livro $O$ Panóptico, no qual ele descrevia uma forma de arquitetura que permitiria a vigilância e o controle contínuo dos indivíduos. Bentham propôs uma espécie de modelo arquitetural de instituição que deveria valer para escolas, hospitais, prisões, hospícios, fábricas, etc. De acordo com Foucault, o panóptico seria a expressão máxima do poder disciplinar, concentrando em si todos os procedimentos disciplinares:

[...] na periferia, uma construção em anel; no centro, uma torre, esta possui grandes janelas que se abrem para a parte inferior do anel. A construção periférica é dividida em celas, cada uma ocupando toda a largura da construção. Estas celas têm duas janelas: uma abrindo-se para o interior, correspondendo às janelas da torre; outra, dando para o exterior, [...]. Basta então colocar um vigia na torre central e em cada cela trancafiar um louco, um doente, um condenado, um operário ou um estudante (FOUCAULT, 2004, p. 210). 
Bentham, ao anunciar tal modelo arquitetural, proporcionaria os meios de destrancar as disciplinas, e fazê-las passar de uma instituição a outra de forma muito eficaz. É um modelo arquitetural, mas também uma forma de se exercer o poder.

A questão é: não é que tenhamos escolas exatamente com esta disposição arquitetural, mas o que vale é o princípio fundamental da ideia de Bentham, isto é, vislumbrar que a própria disposição arquitetural das mais variadas instituições pudesse possibilitar uma vigilância ininterrupta, a qual proporcionaria o controle sobre os indivíduos sem maiores esforços; é somente a disposição arquitetural somada ao olhar que vigia, e o melhor, este olhar pode ser hierárquico: por exemplo: o carcereiro observa o preso; $\mathrm{o}$ inspetor observa o carcereiro, e assim por diante. Na escola vemos toda esta disposição hierárquica e o poder se exercendo por intermediações, através de redes: do diretor ao faxineiro. É toda uma complexa rede de poder que se estende no âmbito da escola.

Nas escolas, as salas são dispostas em corredores uma ao lado da outra; nos corredores temos aqueles que observam os alunos; e aqueles que observam os alunos são observados pelo diretor; etc. os pátios são abertos sem obstáculos, passíveis de serem observados sob vários ângulos. E por vezes, as escolas têm um formato em $U$ e no centro o pátio; e em outros casos um formato retangular, etc; dois formatos bem apropriados para a vigilância e consequente controle. Observação que deve ser anotada, pois a disciplina requer além da vigilância hierárquica, uma produção de anotações e registros, os quais, por sua vez, se transformam em arquivos, em saber sobre o indivíduo. Portanto, vemos se delinear uma escrita também ininterrupta sobre o comportamento, os gestos. E a partir daí uma micro penalidade extrajudicial se faz presente: advertências; suspensões; expulsões.

Dentro da hierarquia que se estabelece entre os indivíduos, que compõem o contexto escolar (gestores, professores, alunos; funcionários e a família), existe uma relação de poder que é "constitutiva de qualquer relação social ou discursiva" (GUIRADO, 1996, p. 59). Não se pode esquecer que, tratando-se do contexto escolar, o poder disciplinar, a relação de poder observada é aquela também existente e estabelecida na sala de aula, na relação professor e aluno, durante o processo de ensino e de aprendizagem. O poder aqui evidenciado não é o poder apenas como quem pode mais ou como impedimentos, restrições, tolhimentos, proibições, onde o aluno é apenas um mero espectador das atividades desenvolvidas na sala de aula, mas, o poder tecido nas interações no âmbito da instituição social e formal 
da escola, na sala de aula, como "poder disciplinar", onde as relações de poder ocorrem no momento de interação recíproca e influenciam na produção de saber, ou seja, dentro da ótica foucaultiana;

[...] poder produz saber [...] poder e saber estão diretamente implicados; que não há relação de poder sem constituição correlata de um campo de saber, nem saber que não supunha e não constitua ao mesmo tempo relações de poder (FOUCAULT, 1987, p. 30).

Por tudo isto, é possível afirmar que a escola é uma instituição disciplinar, isto é, um suporte para o exercício do poder disciplinar. Contudo, uma instituição disciplinar em crise. Por quê? De acordo com o filós ofo francês: "a disciplina, que era eficaz para manter o poder, perdeu uma parte de sua eficácia. Nos países industrializados, as disciplinas entram em crise" (FOUCAULT, 2006, p. 268). Esta afirmação é de 1978 e, acreditamos, tinha sua importância em especial nos Estados Unidos da América e na Europa Ocidental. Hoje, é provável que valha para a nossa sociedade também. Tal crise se deu, sobretudo, pelos fortes movimentos de resistência da segunda metade do século XX: feminismo; movimentos de estudantes; movimentos operários; movimento antipsiquiatria. Pois, na medida em que se tem relações de poder se tem também resistência, há uma relação de imanência. E esta última tornou-se muito contundente no que se refere ao exercício do poder disciplinar. Tanto que assistimos hoje a"falência", ou remanejamentos e tentativas de renovações desesperadas de muitas instituições modernas, tal como a escola. Embora, saiba-se que o que se passa não é uma "falência" pura e simples da escola, ou seja, da instituição. Pois, para se manter fiel ao que temos argumentado até aqui, devemos dizer que se trata de um enfraquecimento das técnicas disciplinares na medida em que se tem, todavia, uma forte insubmissão a elas e, no limite, resistência a elas. E eis que alguém poderia questionar: "vocês afirmam que o desleixo dos alunos, no fundo é um tipo de resistência?". Não sabemos, talvez. O que é possível notar é que o poder disciplinar, cada vez mais, se torna caduco, inoperante, ineficaz, de modo que a escola não funciona mais. E talvez seja a hora desse modelo de escola disciplinar muito característico do século XIX ser abandonado. O que virá? Não sabemos. O fim da escola? Quem sabe sim. A escola (o colégio, o internato) nem sempre existiu. E pode ser que um dia ela feche as portas de uma vez. Ou consiga se reorganizar, como vem tentando, sobre outras formas de poder. $O$ fato é que na perspectiva foucaultiana, o poder disciplinar já estava em crise desde a metade do século XX. Portanto, não é de se espantar que a escola também esteja. 


\section{CONSIDERAÇÕES FINAIS}

Com o que foi arrolado até agora é possível notar que o poder disciplinar é aquele que esteve presente também nas escolas, e que talvez algumas de suas técnicas ainda que já enfraquecidas, com pouca eficácia ainda permaneça lá. Atualmente, os alunos (e talvez todos aqueles que pela escola passam diariamente: professores e demais funcionários) já não se sujeitam mais facilmente a tais técnicas disciplinares, na verdade, basta observar as escolas de nosso país, para constatarmos que este modelo de instituição, com este tipo de poder que herdamos do século XVIII, parece não ter sentido de ser tal como é.

Desse modo, àqueles a que escola está destinada a atender, sobretudo aos alunos, não se interessam mais por ela nos moldes em que ela hoje existe. O que nos resta é pensar em outro molde de escola, outros modos de relação, para quem sabe assim, talvez, oferecer uma educação formal mínima aos estudantes, a qual possa ser significativa para a vida deles. Indo além do implícito, ou talvez, explícito adestramento de indivíduos.

Portanto, compreender as relações de poder, valores, bem como as regras que estão envolvidas na relação professor-aluno, durante o processo de ensino e aprendizagem pode contribuir para melhoria desta relação, pode facilitar a aprendizagem, a construção do conhecimento, obtendo-se assim o êxito escolar, em uma via de mão dupla, considerando-se as aprendizagens construídas pelos alunos, por meio dos conteúdos que são ensinados pelo professor na sala de aula.

Acredita-se também, que o sistema de controle existente nas relações de poder, não deve objetivar apenas o controle e a disciplina no contexto escolar, ou subsidiar apenas quem "tem" o maior poder, mas deve objetivar também um poder comprometido do professor, usado para criar uma relação de maior proximidade com os alunos, onde este busca manter um ambiente propício à aprendizagem, mas ao mesmo tempo procura respeitar seus alunos.

Mas, isto já está além dos esforços apresentados neste artigo. Procurou-se, tão somente, apresentar uma breve reflexão, um diagnóstico, da escola atual a partir dos conceitos e estudos Foucaultianos. Estamos certos de que esta apresentação não tem a pretensão de ser uma verdade indubitável, mas que seja apenas uma perspectiva sobre o assunto abordado. 
THINKING THE SCHOOL FROM FOUCAULT'S PERSPECTIVE: A DISCIPLINARY INSTITUTION IN CRISIS?

ABSTRACT: The aim of this paper is to present a perspective on discipline, based on the thought of the French philosopher Michel Foucault, within the school context in contemporary society where the student no longer easily accepts disciplinary techniques. To do so, we use the concept of disciplinary power and seek to characterize the school as an institution in which that power is exercised. We also present some thoughts and considerations about another possible school that seeks to provide minimal formal education for students, which would go beyond the mere training of individuals and could be important for their lives. From these assumptions, we can only wonder: is the current school a disciplinary institution in crisis? Using our research as a diagnosis, we respond affirmatively to that question.

KEYworDs: Foucault. Power. Discipline. School.

PENSAR LA ESCUELA A PARTIR DE FOUCAULT: ¿UNA INSTITUCIÓN DISCIPLINARIA EN CRISIS?

RESUMEN: El presente artículo tiene como objetivo presentar, a partir del filósofo francés Michel Foucault, una perspectiva de la disciplina dentro del contexto escolar en la sociedad contemporánea, en la cual, el alumno ya no acepta fácilmente las técnicas disciplinarias. Para tal, utilizamos el concepto del poder disciplinario y buscamos caracterizar la escuela como una institución en la que se ejerce ese poder. También presentamos algunas reflexiones y consideraciones sobre otra escuela posible que busque ofrecer una educación formal mínima a sus estudiantes, que pueda ser importante para sus vidas, yendo más allá del mero adiestramiento de los individuos. A partir de tales premisas, sólo nos queda indagar: ¿es la escuela actual es una institución disciplinaria en crisis? De acuerdo con nuestra investigación y su diagnóstico, respondemos afirmativamente a este interrogante.

Palabras claves: Foucault. Poder. Disciplina. Escuela.

\section{NOTAS}

1) Em "História da loucura", de 1961 encontra-se uma análise sobre o internamento: $1^{\circ}$ - um internamento geral; $2^{\circ}$ - um internamento específico. Respectivamente sobre o Hospital Geral e o asilo psiquiátrico. Acreditamos que nessas análises de Foucault constam um estudo sobre um tipo de poder. 
2) Não faremos aqui uma análise do texto de Bentham, mas nos ocuparemos dos estudos de Foucault sobre o autor.

3) Talvez Foucault tenha feito análise institucional, sobretudo em "História da loucura", mas na década de 1970 - e é este o período de seu pensamento que mais nos importa, o autor concentrou-se nas relações de poder. As instituições sendo compreendidas, nesse momento, como suportes para tais relações.

4) Ainda que ele já tivesse uma história anterior ao século XVIl; contudo, é a partir daí que ele se amplia e se generaliza cada vez mais. FOUCAULT, Michel. "O poder psiquiátrico": curso dado no Collège de France (1973-1974). Trad. Eduardo Brandão. São Paulo: Martins Fontes, 2006. p. 79-116

\section{REFERÊNCIAS:}

DEFERT, D. Cronologia. In: FOCAULT, Michel. Ditos e Escritos: psicologia, psiquiatria, psicanálise. Rio de Janeiro: Forense Universitária, 1999. v. I.

FOUCAULT, M. Vigiar e Punir: nascimento da prisão. Tradução de Raquel Ramalhete. 37. ed. São Paulo: Vozes, 2009.

. História da Loucura na Idade Clássica. Tradução de José Teixeira Coelho Neto. São Paulo: Perspectiva, 2008.

. A sociedade disciplinar em crise. In: Ditos e Escritos: estratégia, poder-saber. Rio de janeiro: Forense Universitária, 2006. v. IV.

. O Poder Psiquiátrico: curso dado no Collège de France (1973-1974). Tradução de Eduardo Brandão. São Paulo: Martins Fontes, 2006.

. Microfísica do Poder. Tradução de Roberto Machado. 19. ed. Rio de Janeiro: Edições Graal, 2004.

Sobre as prisões. In: Ditos e Escritos: estratégia, poder-saber. Rio de janeiro: Forense Universitária, 2003. v. IV.

GALLO, S. Foucault: (re)pensar a educação. In: .RAGO, M.; VEIGA-NETO, A. (org.). Figuras de Foucault. 2. ed. Belo Horizonte: Autêntica, 2008.

GUIRADO, M. Poder e indisciplina: os surpreendentes rumos da relação de poder. In: AQUINO, J. G. (Org.). Indisciplina na Escola: alternativas teóricas e práticas. São Paulo: Summus, 1996.

RABINOW, P.; DREYFUS, H. Michel Foucault, uma Trajetória Filosófica: para além do estruturalismo e da hermenêutica. Rio de janeiro: Forense Universitária, 1995.

REVEL, J. Dicionário Foucault. Rio de Janeiro: Forense Universitária, 2011. 
FABIO BATISTA é graduado em História e Filosofia pela Universidade Estadual do Norte do Paraná (UENP), possui especialização em História, Cultura e Sociedade pela mesma universidade. Atualmente, é mestrando do programa de pós-graduação em Filosofia da Universidade Estadual de Londrina (UEL). Possui interesse em Filosofia Contemporânea, concentrando seus estudos em Foucault, com ênfase nos seguintes temas: poder, poder disciplinar, biopolítica, corpo e violência.

E-mail: fabiobatista1985@bol.com.br

Ana lúcia Pereira Baccon é graduada em Ciências e Matemática pela Universidade Estadual do Norte do Paraná (UENP), mestre e doutora em Ensino de Ciências e Educação Matemática pela Universidade Estadual de Londrina (UEL). Professor Adjunto na Universidade Estadual de Ponta Grossa (UEPG), no Departamento de Matemática e Estatística. Atualmente, é vice-coordenadora do Programa de Pós-Graduação em Educação (Mestrado e Doutorado). Desenvolve pesquisas nas seguintes linhas: Formação de professores; Ensino e aprendizagem; Psicanálise e Educação Matemática.

E-mail:ana.baccon@hotmail.com

FÁbio Antonio Gabriel é licenciado em Filosofia pela Faculdade Padre João Bagozzi e bacharel em Teologia pela Pontifícia Universidade Católica do Paraná (PUCPR). Possui especialização em Filosofia e Ética pela Faculdade do Noroeste de Minas (FINOM) e especialização em Metodologia do Ensino de Filosofia e Sociologia. Atualmente, é professor do Quadro Próprio de Magistério da SEED/PR, professor supervisor PIBID CAPES/UENP, e mestrando em educação na Universidade Estadual de Ponta Grossa.

E-mail: fabioantoniogabriel@gmail.com 